A s i a $\mathrm{n}$ o u r nal of

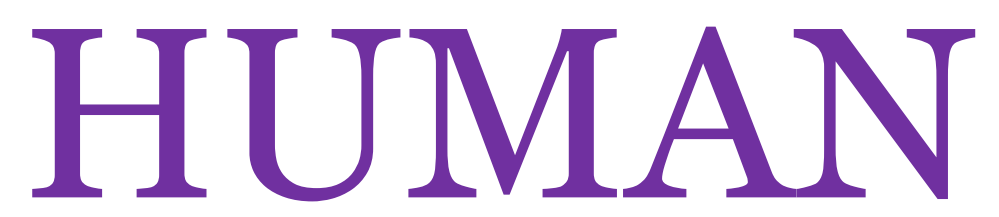

Printed 2018.1030 ISSN2188-059X

Published by Asian Society of Human Services

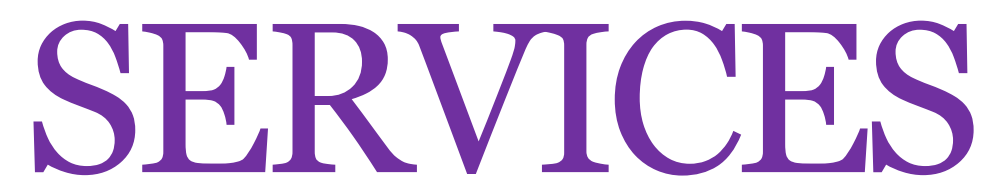

$\left.O_{\text {ctober } 2018}\right\rceil 5$
VOL.

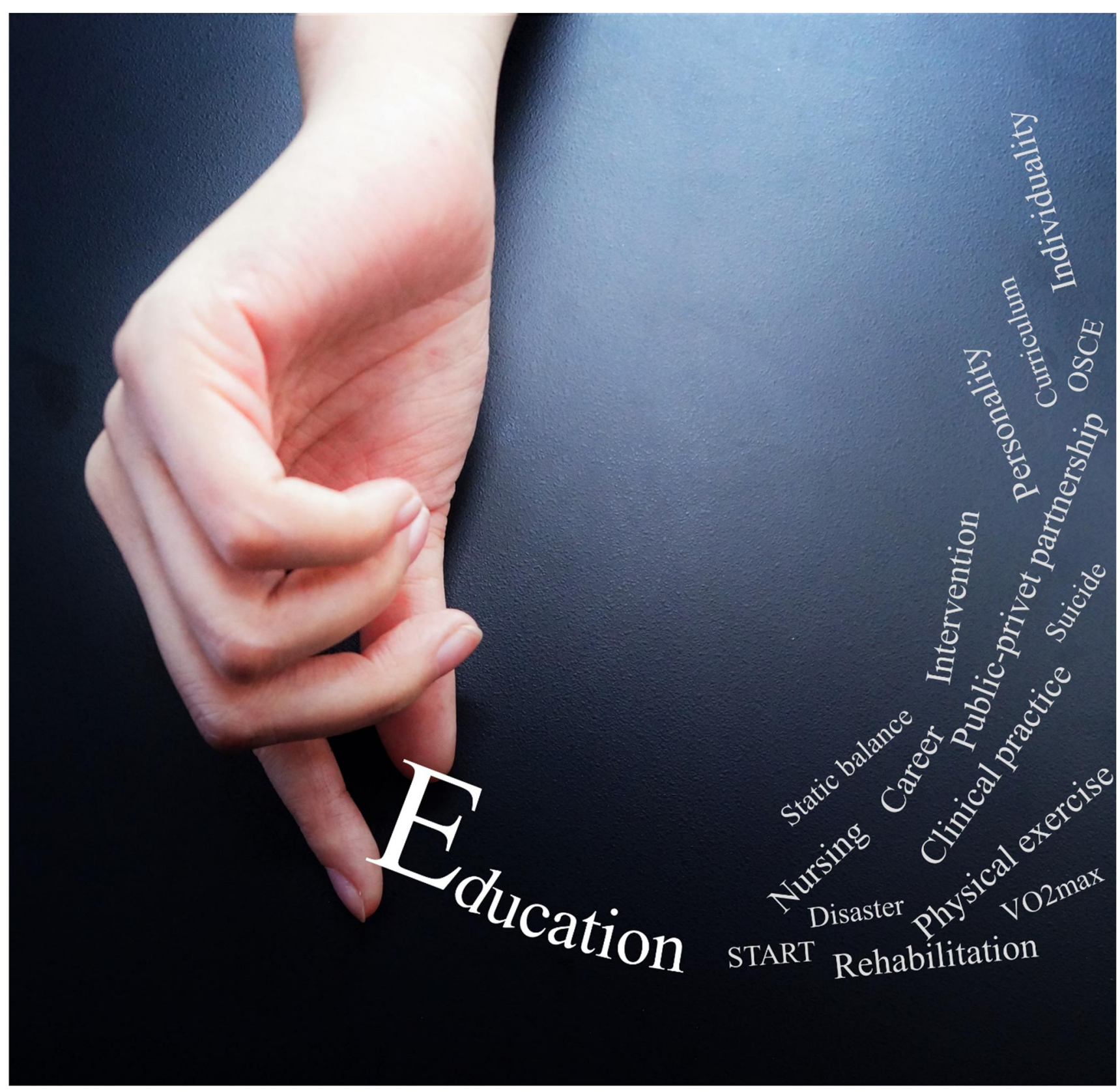


Review Article

\section{Importance of Physical Exercise in Oldest-old Adults:}

\section{A Literature Review Study}

\author{
Chaeyoon CHO 1) Chaewon LEE 1) Masahiro KOHZUKI 1)
}

1) Graduate School of Medicine, Tohoku University, Japan

\begin{abstract}
Oldest-old adults aged $\geq 85$ years are more vulnerable to frailty, chronic diseases, and disabilities; therefore, concerns about their healthcare are increasing. Prevention of physical and mental disability is a key objective for successful ageing in these adults. We aim to review the literature investigating the importance of exercise in oldest-old adults. Moreover, our major goal is to present the effectiveness of exercise designed to improve physical function in oldest-old adults. An effective exercise protocol for oldest-old adults is characterized by an intervention period of 24 weeks, intervention frequency of 2 or 3 times per week, and intensity of reserve heart rate ranging from 40 to $60 \%$. Although exercise intervention had a uniformly positive impact on physical function, regular physical exercise seemed to be more beneficial in oldest-old adults. Further studies are necessary to investigate the systematic review in physical exercise and oldest-old adults.
\end{abstract}

\section{$<$ Key-words $>$}

intervention, oldest-old adults, physical exercise, physical performance.

\section{Received}

September 27, 2018

Revised

October 12, 2018

Accepted

October 15, 2018

Published

October 30, 2018
Corresponding author: kohzuki@med.tohoku.ac.jp (Masahiro KOHZUKI; Japan) Asian J Human Services, 2018, 15:93-100. ㅇ 2018 Asian Society of Human Services 


\section{Super-Aged Society: older population.}

The World Health Organization (WHO) defined an "aging society" as one in which more than $7 \%$ of the population is 65 years or older, an "aged society" as a society in which more than $14 \%$, and a "super-aged society" as a society in which more than $21 \%$ (Tahara, 2016). Since 2013, Japan has been a super-aged society in which more than $25 \%$ of the population is 65 years or older (Tahara, 2016; Arai, Ouchi, Toba et al., 2015).

In Japan, the population dynamics in the last half century (1950s to 2010s) show drastic changes. In the $1950 \mathrm{~s}$, the older adult population occupied merely $5 \%$ of the total population, and the life expectancy was only approximately 60 years. In contrast, since 2017, Japan has been a super-aged society in which more than $28 \%$ of the older adult population (Arai, Ouchi, Toba et al., 2015; Suzuki, 2018).

As of 2017, the total Japanese population was 126.7 million, which included 35.2 million people aged $\geq 65$ years $(27.7 \%)$ and 17.5 million people aged $\geq 75$ years (13.8\%). Henceforth, the oldest-old (aged $\geq 85$ years) and old-old (aged $\geq 75$ years) population will increase rapidly compared with the young-old population (aged 65-74 years) in Japan (Suzuki, 2018). In other words, 1 in 4 Japanese individuals is an older adult. The population of Japan is predicted to continue to grow in the future (Suzuki, 2018). In addition, the 2017 statistics revealed an average life expectancy of approximately 87 and 81 years in women and men, respectively.

Older age has been shown to be a risk factor for age-related decline in specific areas, physical decline predisposes to loss of independence, poor quality of life, and hospitalization (Arai, Iinuma, Takayama et al., 2010; La Grow, Yeung, Towers et al., 2013). Particularly, oldest-old adults aged $\geq 85$ years are more vulnerable to chronic diseases and disabilities; therefore, concerns about their healthcare are increasing (Ansai, Aurichio, Gonçalves et al., 2016). Moreover, prevention of physical and mental disability is a key factor for successful ageing in oldest-old adults (Ansai, Aurichio, Gonçalves et al., 2016; Orr, de Vos, Singh et al., 2006)

\section{Geriatric Syndrome: "Frailty" and "Frail"}

Frailty is the term used to indicate a geriatric syndrome characterized by reduced homeostatic reserves, which exposes the individual to an increased risk of negative health-related events, such as falls, disability, hospitalizations, and mortality (Rodríguez-Mañas, Féart, Mann et al., 2012; Clegg, Young, Iliffe et al., 2013). Different operational definitions have been proposed for capturing frailty status, with each one focusing on specific aspects of the syndrome and detecting slightly different risk profiles (Cesari, Landi, Vellas et al., 2014). The terms frailty and frail are often used in the literature without clear criteria; there is not yet a consensus on a standardized and valid method for clinical screening of frailty. The most well-known definition is the frailty 
phenotype described by Fried et al (Fried, Tangen, Walston et al., 2001; Fried, Xue, Cappola et al., 2009)

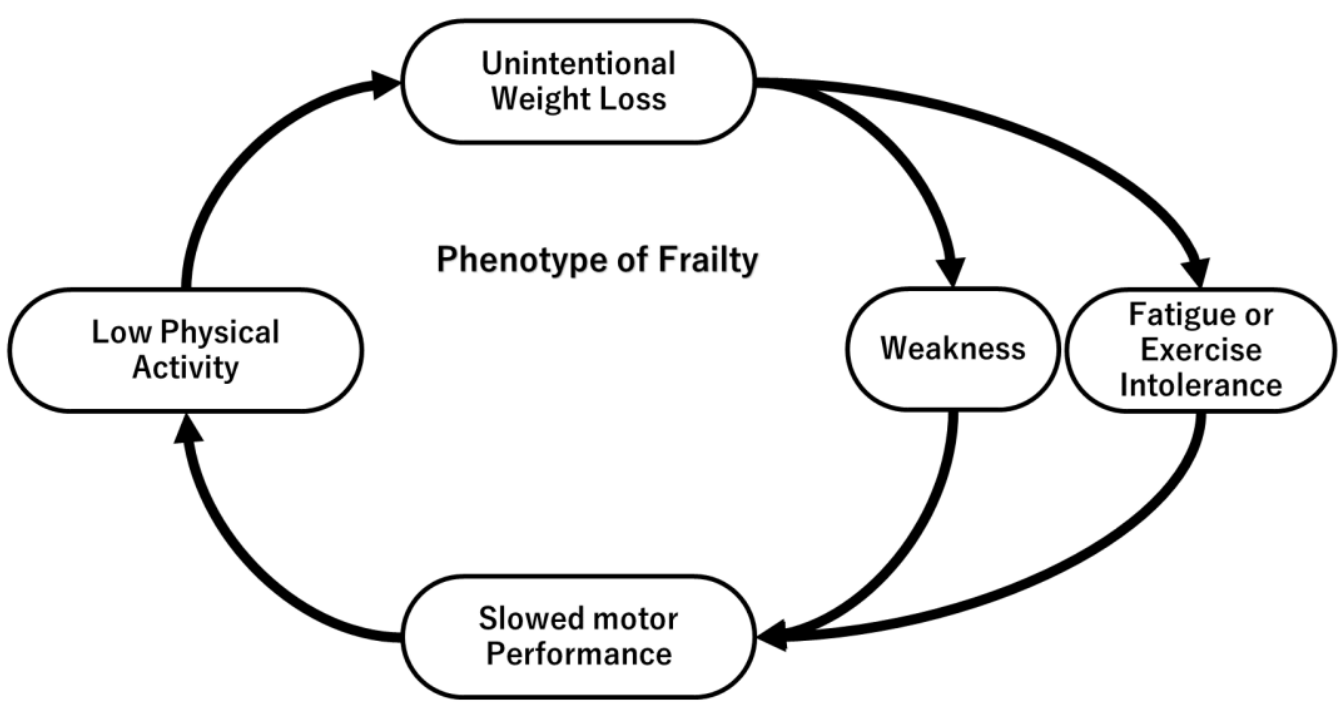

(Adapted from Fried LP, et al. J Geronrol A Biol Sci Med Sci. 2009; Liu CK, et al. Cli Geriatr Med. 2011)

$<$ Figure 1> Component frailty

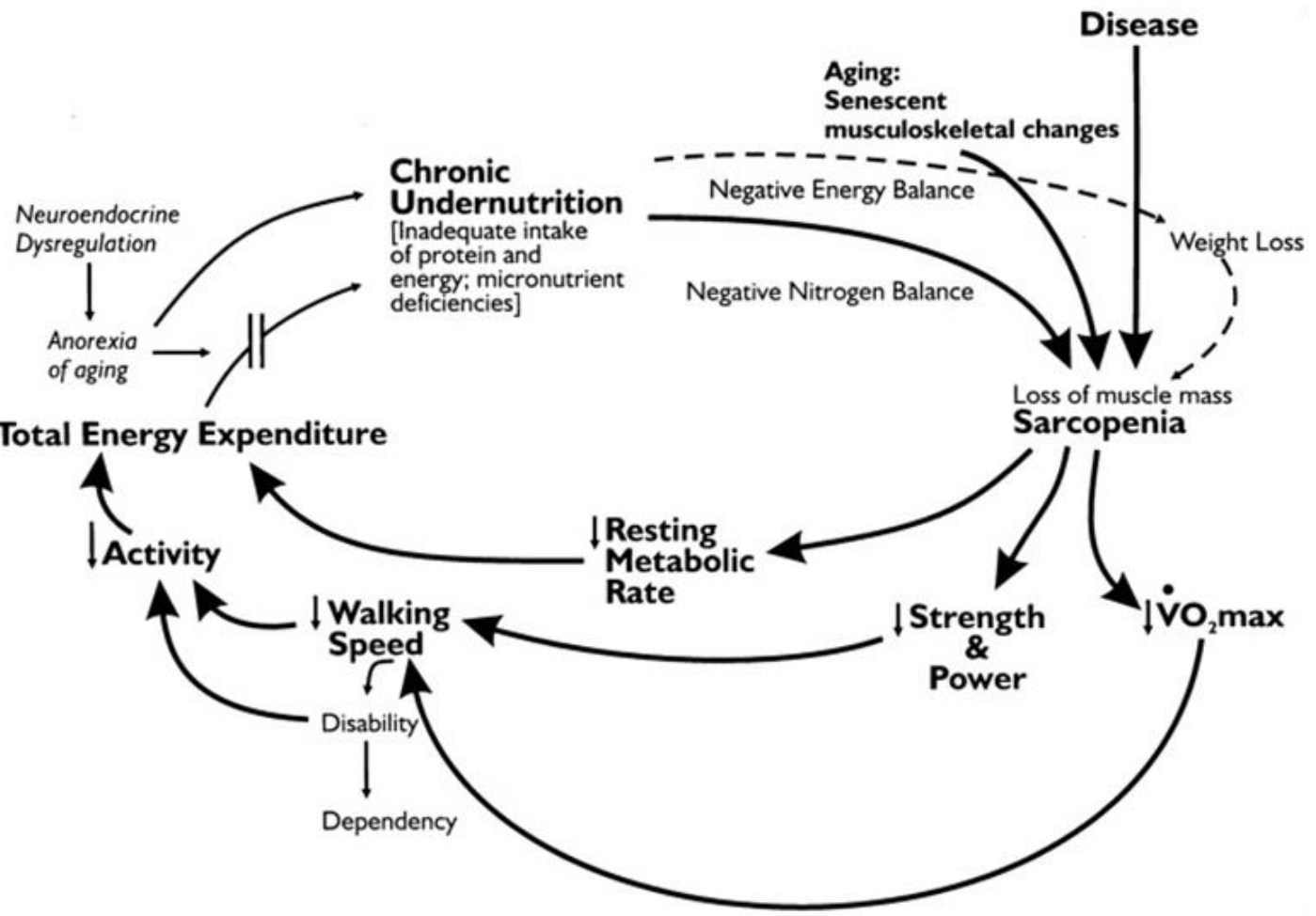

(Adapted from Fried LP et al, . J Gerontol A viol Sci Med Sci. 2001.

Negm AM, et al. Pilot Feasibility Study. 2018)

$<$ Figure 2> Frailty Cycle 
Fried et al. characterized frailty as unintentional weight loss ( $\geq 4.5 \mathrm{~kg}$ in the past year), weakness, fatigue or exercise intolerance, slowed motor performance, and low physical activity in individuals (Fig 1). Older adults were considered pre-frail if they had 1 or 2 of these characteristics; they were considered frail if they demonstrated at least 3 of these characteristics (Fried, Xue, Cappola et al., 2009; Liu \& Fielding et al., 2011).

In addition, the cycle of frailty model proposed by Fried et al in 2001 (Fig. 2) identified key elements of frailty (Fried, Tangen, Walston et al., 2001; Negm, Kennedy, Ioannidis et al., 2018). The core elements of the frailty cycle incorporated the main frailty markers, including age-associated physical declines in activity, strength, balance, and walking speed (Liu \& Fielding et al., 2011). The proposed intervention components aimed to improve all frailty markers of the frailty cycle (Fig 2 ).

Pre-frail oldest-old adults have an increased risk of falls, hip fractures, and disability as well as of becoming subsequently more frail than young-old adults (Woods, LaCroix, Gray et al., 2005; Shirooka, Nishiguchi, Fukutani et al., 2017). Therefore, maintaining a non-frail and healthy status is important for prevention of various adverse outcomes. This prevention requires exercise interventions plus the treatment of disability aimed at reducing the risks of complications in older adults.

\section{Physical Exercise in oldest-old adults: literature review}

In recent years, increased physical exercise and exercise intervention have been proposed as preventive strategies for frailty and its adverse outcomes, as they can target 4 of the frailty criteria. This literature review aims to investigate the effect of exercise interventions on improving physical function in oldest-old adults (Ansai, Aurichio, Gonçalves et al., 2016; Cho, Han, Sung et al., 2017; Kapan, Winzer, Haider et al., 2017). Three studies published between 2016 to 2017 were included in the review. Two studies were randomized control trials (RCTs) and one were nonrandomized control trials (NRCTs).

Table 1 presents the characteristics and summary of the exercise interventions. The researched studies encompassed a sample population of 59 oldest-old adults, with a mean age of $84.3 \pm 3.7$ years. Exercise time of three studies, ranging from 16(Ansai, Aurichio, Gonçalves et al., 2016), 24(Kapan, Winzer, Haider et al., 2017) to 48h (Cho, Han, Sung et al., 2017) over 16 to 24 weeks reported statistically significant improvements in physical function; strength and balance.

One of the 3 studies used multicomponent exercise with aerobic, strength, and balance exercises (Ansai, Aurichio, Gonçalves et al., 2016). One study included aerobic exercise (Cho, Han, Sung et al., 2017) and one included strength exercise (Kapan, Winzer, Haider et al., 2017). Two of the studies used an ergometer machine for aerobic exercise (Ansai, Aurichio, Gonçalves et al., 2016; Cho, Han, Sung et al., 2017). Two studies used the following strength exercises: (1) exercise intensity ranging from 14 to 17 on the Borg 
conventional scale; progression was carried out by increasing to 15 repetitions and an incremental load of $1 \mathrm{~kg}$ (Ansai, Aurichio, Gonçalves et al., 2016) and (2) exercise performed in two sets, with 12-15 repetitions until muscular exhaustion (Kapan, Winzer, Haider et al., 2017).

$<$ Table $1>$ Summary of study details for papers included in literature review

\begin{tabular}{|c|c|c|c|}
\hline Study & $\begin{array}{c}\text { Participants } \\
\text { and Intervention }\end{array}$ & Exercise Intensity & $\begin{array}{l}\text { Outcomes } \\
\text { and Findings }\end{array}$ \\
\hline \multirow[t]{2}{*}{$\begin{array}{l}\text { Ansai, } \\
\text { Aurichio, } \\
\text { Gonçalves } \\
\text { et al., } \\
(2016)\end{array}$} & \multirow{2}{*}{$\begin{array}{l}\mathrm{RCTs} \\
\mathrm{n}=23 \text {, } \\
\text { community-dwelling healthy. } \\
\text { Age, mean } \pm \text { SD: } 82.6 \pm 2.6 \\
\text { Multicomponent Exercise } \\
(60 \mathrm{~min} / \mathrm{session} \text {, } \\
\text { 1time/week,4-month) } \\
\text { 1) } 5 \text { min of warm-up } \\
\text { 2) } 13 \text { min of aerobic exercise } \\
\text { 3) } 15-20 \text { min of strength exercise } \\
\text { 4) } 10 \text { min of balance exercise. } \\
\text { 5) } 5 \text { min of cool-down }\end{array}$} & \multirow{2}{*}{$\begin{array}{l}\text { Aerobic exercise: } \\
\text { ranged } 60 \text { to } 85 \% \\
\text { reserve heart rate. } \\
\text { Strength exercise: } \\
\text { ranged from } 14 \text { to } 17 \text { on } \\
\text { the borg scale. } \\
\text { Balance exercise: } \\
\text { Dynamic and static } \\
\text { weight transfer, } \\
\text { Walking on a line. }\end{array}$} & $\begin{array}{l}\text { Outcomes } \\
\text { 1)Muscle strength: } \\
\text { sit-to-stand } \\
\text { 2) Balance: one-leg } \\
\text { standing } \\
\text { 3) dual task: TUG } \\
\text { 4) Falls }\end{array}$ \\
\hline & & & $\begin{array}{l}\text { Findings } \\
\text { Significant increase } \\
\text { in muscle strength } \\
\text { and balance, } \\
\text { no significant dual } \\
\text { task and Falls. }\end{array}$ \\
\hline \multirow[t]{2}{*}{$\begin{array}{l}\text { Cho, Han, } \\
\text { Sung } \\
\text { et al., } \\
(2017)\end{array}$} & \multirow{2}{*}{$\begin{array}{l}\text { NRCTs } \\
\mathrm{n}=10 \text {, } \\
\text { community-dwelling healthy. } \\
\text { Age, mean } \pm \mathrm{SD}: 85.2 \pm 2.4 \\
\text { Aerobic Exercise } \\
\text { (40min/session, } \\
3 \text { time/week, } 6 \text {-month) } \\
\text { 1) } 5 \text { min of stretching(warm-up) } \\
\text { 2) } 30 \text { min of aerobic } \\
\text { 3) } 5 \text { min of stretching(cool-down) }\end{array}$} & \multirow[t]{2}{*}{$\begin{array}{l}\text { Aerobic Exercise: } \\
\text { ranged from } 40 \text { to } 60 \% \\
\text { reserve heart rate. } \\
\text { Borg scale of 11(light) } \\
\text { to13(Somewhat hard). }\end{array}$} & $\begin{array}{l}\text { Outcomes } \\
\text { 1)SPPB: } \\
\text { 3test balance, } \\
\text { gait speed, } \\
\text { lower strength. } \\
\text { 2) QOL: SF-12 }\end{array}$ \\
\hline & & & $\begin{array}{l}\text { Findings } \\
\text { Significant increase } \\
\text { in SPPB } \\
\text { total score, } \\
\text { balance, } \\
\text { lower strength, } \\
\text { SF-12. } \\
\text { No significant gait } \\
\text { speeds }\end{array}$ \\
\hline \multirow[t]{2}{*}{$\begin{array}{l}\text { Kapan, } \\
\text { Winzer, } \\
\text { Haider } \\
\text { et al. } \\
(2017)\end{array}$} & \multirow{2}{*}{$\begin{array}{l}\text { RCTs } \\
\text { n= } 26 \text {, pre-frail. } \\
\text { Age, mean } \pm \text { SD: } 84.0 \pm 6.0 \\
\text { Physical Exercise } \\
\text { (60min/session, } \\
2 \text { time/week,3-month) } \\
\text { 1) } 5 \text { min of warm-up } \\
\text { 2) } 50 \text { min of six strength exercise } \\
\text { 3) } 5 \text { min of cool-down }\end{array}$} & \multirow[t]{2}{*}{$\begin{array}{l}\text { Six strength exercise: } \\
\text { ranged } 12 \text { to } 15 \\
\text { repetitions. }\end{array}$} & $\begin{array}{l}\text { Outcomes } \\
\text { 1) SPPB, } \\
\text { 2)handgrip } \\
\text { strength, } \\
\text { 3) PASE } \\
\text { 4) WHOQoL }\end{array}$ \\
\hline & & & $\begin{array}{l}\text { Findings } \\
\text { Significant increase } \\
\text { in SPPB } \\
\text { total score, } \\
\text { PASE total score, } \\
\text { no significant } \\
\text { handgrip strength } \\
\text { and WHOQoL. }\end{array}$ \\
\hline
\end{tabular}

Note: NRCTs; nonrandomized control trial. PASE; Physical Activity Scale for the Elderly, RCTs; randomized control trial. SPPB; Short physical Performance Battery, TUG; Timed Up and Go test. WHOQoL; World Health Organization Quality of Life, SF-12; 12-Item Short-Form Health Survey. 
Table 1 also presents the outcomes and significance values of the 3 included studies. All studies reported statistically significant effects of physical function, such as muscle strength, lower body strength, and balance (Ansai, Aurichio, Gonçalves et al., 2016; Cho, Han, Sung et al., 2017; Kapan, Winzer, Haider et al., 2017). Moreover, one study showed a significant on health-related quality of life (Cho, Han, Sung et al., 2017). Multicomponent and aerobic exercises appeared to have the greatest impact. These studies have shown that physical exercise in oldest-old adults protects against the diverse components of frailty by increasing muscle strength and balance.

\section{Conclusion}

In a literature review of the importance of exercise interventions for the frailty and frail in oldest-old adults. It was found that even though the participants were oldest-old and frail, the exercise adherence was high with no adverse events, supporting that exercise was safe and feasible (Ansai, Aurichio, Gonçalves et al., 2016; Cho, Han, Sung et al., 2017; Kapan, Winzer, Haider et al., 2017).

An effective exercise protocol for oldest-old adults is characterized by an intervention period of 24 weeks over, an intervention frequency of two or three times per week, intensity of ranged from 40 to $60 \%$ reserve heart rate. Although exercise intervention uniformly had a positive impact on physical function, regular physical exercise seemed to be more beneficial in oldest-old adults.

In conclusion, Regular exercise intervention in physical and mental function is a key point for successful ageing in oldest-old adults. However, this study is literature review, further studies are necessary to investigate the systematic review in physical exercise and oldest-old adults.

\section{References}

1) Tahara Y. (2016) Cardiopulmonary Resuscitation in a Super-Aging Society-Is There an Age Limit for Cardiopulmonary Resuscitation? Circulation. 80(5): 1102-1103. doi: 10.1253/circj.CJ-16-0307

2) Arai H, Ouchi Y, Toba K, Endo T, Shimokado K, Tsubota K, et al. (2015) Japan as the front-runner of super-aged societies: Perspectives from medicine and medical care in Japan. Geriatr Gerontol Int 15: 673-687. doi: 10.1111/ggi.12450.

3) Suzuki T. (2018) Health status of older adults living in the community in Japan: Recent changes and significance in the super-aged society. Geriatr Gerontol Int. 18(5):667-677. doi: 10.1111/ggi.13266. 
4) Arai Y, Iinuma T, Takayama M, Takayama M, Abe Y, Fukuda R, et al. (2010) The Tokyo Oldest Old survey on Total Health (TOOTH): a longitudinal cohort study of multidimensional components of health and well-being. BMC Geriatr. 2010; 10:35. doi: 10.1186/1471-2318-10-35.

5) La Grow S, Yeung P, Towers, A, Alpass F \& Stephens C. (2013) The impact of mobility on quality of life among older persons. J Aging Health, 25(5):723-736. doi: $10.1177 / 0898264313490198$.

6) Ansai JH, Aurichio TR, Gonçalves R \& Rebelatto JR. (2016) Effects of two physical exercise protocols on physical performance related to falls in the oldest old: a randomized controlled trial. Geriatr Gerontol Int., 16(4): 492-499. doi: 10.1111/ggi.12497.

7) Orr R, de Vos NJ, Singh NA, Ross DA, Stacrinos TM \& Fiatarone-Singh MA. (2006) Power training improves balance in healthy older adults. J Gerontol A Biol Sci Med Sci, 61, 78-85.doi: 10.1093/gerona/61.1.78.

8) Rodríguez-Mañas L, Féart C, Mann G, Viña J, Chatterji S, Chodzko-Zajko W, et al. (2012) Searching for an operational definition of frailty: a Delphi method based consensus statement. The frailty operative definition-consensus conference project. $J$ Gerontol A Biol Sci Med Sci, 68(1): 62-67.

doi: $10.1093 /$ gerona/gls119

9) Clegg A, Young J, Iliffe S, Rikkert MO \& Rockwood K. (2013) Frailty in elderly people. Lancet. 381(9868):752-762. doi: 10.1016/S0140-6736(12)62167-9.

10) Cesari M, Landi F, Vellas B, Bernabei R \& Marzetti E. (2014) Sarcopenia and Physical Frailty: Two Sides of the Same Coin. Front Aging Neurosci. 6:192. doi: 10.3389/fnagi.2014.00192.

11) Fried LP, Tangen CM, Walston J, Newman AB, Hirsch C, Gottdiener J, et al. (2001) Frailty in older adults: evidence for a phenotype. J Gerontol A viol Sci Med Sci. 56(3): M146-156. doi: 10.1093/gerona/56.3.M146.

12) Fried LP, Xue Q1, Cappola AR, Ferrucci L, Chaves P, Varadhan R, et al. (2009) Nonlinear multisystem physiological dysregulation associated with frailty in older women; implications for etiology and treatment. J Gerontol A viol Sci Med Sci. 64(10):1049-1057. doi: 10.1093/gerona/glp076.

13) Liu CK \& Fielding RA. (2011) Exercise as an Intervention for Frailty. Clin Geriatr Med. 27(1): 101-110. doi: 10.1016/j.cger.2010.08.001.

14) Negm AM, Kennedy CC, Ioannidis G, Gajic-Veljanoski O, Lee J, Thabane L, et al. (2018) Getting fit for hip and knee replacement: a protocol for the Fit-Joints pilot randomized controlled trial of a multi-modal intervention in frail patients with osteoarthritis. Pilot Feasibility Study. 4:127. doi: 10.1186/s40814-018-0316-2. 
15) Woods NF, LaCroix AZ, Gray SL, Aragaki A, Cochrane BB, Brunner RL, et al. (2005) Frailty: emergence and consequences in women aged 65 and older in the women's health initiative observational study. J Am Geriatr Soc. 53 (8):1321- 1330. doi: 10.1111/j.1532-5415.2005.53405.x.

16) Shirooka H, Nishiguchi S, Fukutani N, Adachi D, Tashiro Y, Hotta T, et al. (2017) Association between comprehensive health literacy and frailty level in community-dwelling older adults: A cross-sectional study in Japan. Geriatr Gerontol Int. 17(5):804-809. doi: 10.1111/ggi.12793.

17) Cho C, Han C, Sung M, Lee C, Kim M, Ogawa T, et al. (2017) Six-Month Lower Limb Aerobic Exercise Improves Physical Function in Young-Old, Old-Old, and Oldest-Old Adults. Tohoku J Exp Med. 242(4):251-257. doi: 10.1620/tjem.242.251.

18) Kapan A, Winzer E, Haider S, Titze S, Schindler K, Lackinger C et al. (2017) Impact of a lay-led home-based intervention programme on quality of life in community-dwelling pre-frail and frail older adults: a randomized controlled trial. BMC Geriatr. 17(1):154. doi: 10.1186/s12877-017-0548-7. 
- Editorial Board -

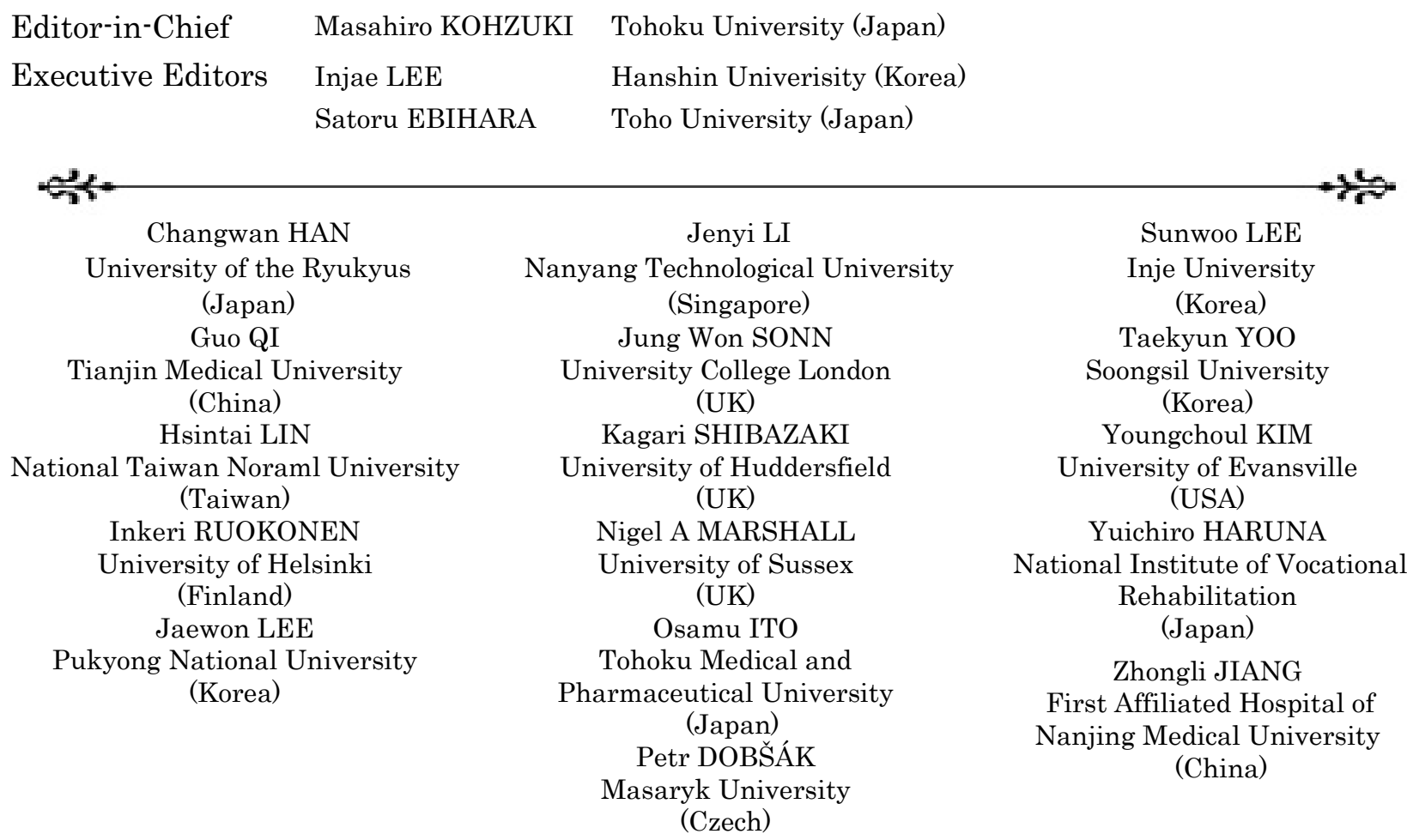

Editorial Staff

- Editorial

Assistants
Aiko KOHARA

Marcus Eije Zantere

Moonjung KIM
University of the Ryukyus (Japan)

University of Gothenburg (Sweden)

Korea Labor Force Development Institute for the aged (Korea)

Natsuki YANO

Tohoku University / University of the Ryukyus (Japan)

\section{Asian Journal of Human Services VOL.15 Ocober 2018}

(C) 2018 Asian Society of Human Services

$\begin{array}{ll}\text { Editor-in-Chief } & \text { Masahiro KOHZUKI } \\ \text { Presidents } & \text { Masahiro KOHZUKI } \cdot \text { Sunwoo LEE } \\ \text { Publisher } & \text { Asian Society of Human Services } \\ & \text { Faculty of Education, University of the Ryukyus, 1 Senbaru, Nishihara, Nakagami, Okinawa, Japan } \\ & \text { FAX: +81-098-895-8420 E-mail: ashs201091@gmail.com }\end{array}$

Production Asian Society of Human Services Press

Faculty of Education, University of the Ryukyus, 1 Senbaru, Nishihara, Nakagami, Okinawa, Japan FAX: +81-098-895-8420 E-mail: ashs201091@gmail.com 


\section{Asian Journal of Human Services \\ VOL.15 October 2018 \\ CONTENTS}

\section{ORIGINAL ARTICLES}

Using Videos to Analyze the Effectiveness of START Education for Japanese Nursing Students

Kazuyuki AKINAGA et al., 1

Effects of the OSCE to Motivate Students to Learn Before Clinical Practice

Yuko FUJIO et al., 13

The Current Status and Its Implications of Public-Private Partnerships for Official Development

Assistance in Korea: Focusing on Disability-Inclusive Development Cooperation

Juhee HWANG et al., 25

Effects of a Structured 8-week Nordic Walking Exercise Program on Physical Fitness in the Japanese Elderly

Study of "Individuality" on Nursing Care Job

Kimiko YAMAMOTO et al., 38

Kimiko YAMAMOTO et al., 52

\section{SHORT PAPERS}

A Comparison of the Factor Structure of the Self-Harm Antipathy Scale and related Demographic Characteristics between Korea and Japan

Yoshimi AOKI et al., 66 Issues of Specific Educational Curriculum Development for Resource Rooms and Special Needs Classes in Japanese High Schools

Mitsuyo SHIMOJO et al., 76

\section{REVIEW ARTICLES}

Importance of Physical Activity and $\dot{\mathrm{V}}_{2}$ max: Five Major Determinants of $\dot{\mathrm{V}}_{2} \max$

Masahiro KOHZUKI et al., 85

Importance of Physical Exercise in Oldest-old Adults: A Literature Review Study

Chaeyoon $\mathrm{CHO}$ et al., 93

Published by

Asian Society of Human Services

Okinawa, Japan 